\title{
DURABILIDADE DE COMPÓSITO BIOMASSA VEGETAL-CIMENTO MODIFICADO POR POLÍMERO ${ }^{1}$
}

\section{LIA L. PIMENTEL ${ }^{2}$, ANTONIO L. BERALDO ${ }^{3}$, HOLMER SAVASTANO JÚNIOR ${ }^{4}$}

RESUMO: A durabilidade de compósito biomassa vegetal-cimento é um dos fatores mais importantes para a colocação desse material no mercado consumidor. A utilização de polímeros em concreto e argamassa, com o objetivo de melhorar sua durabilidade, é cada vez mais freqüente. Este estudo visou à caracterização de propriedades físicas e mecânicas de compósito biomassa vegetal-cimento modificado com polímeros e a análise da durabilidade desse compósito. Foi testado um polímero de base acrílica em compósitos produzidos com resíduo de Pinus caribaea. Foram realizados ensaios de envelhecimento acelerado, por meio de ciclos de molhamento e secagem, por imersão em água quente e ensaio de envelhecimento natural. As propriedades físicas do compósito avaliadas foram a massa específica aparente e a absorção total de água por imersão. As propriedades mecânicas foram determinadas por meio de ensaios de resistência à tração na flexão, analisando-se a tensão e a energia de ruptura. Os corpos-de-prova foram extraídos de placas executadas por simples prensagem. Ensaios de microscopia eletrônica de varredura foram utilizados para observar o estado da fibra e da matriz após os processos de envelhecimento. O uso de polímero melhorou o desempenho mecânico do compósito nas primeiras idades e também promoveu significativa redução da capacidade de absorção de água, demonstrando que o uso desse material pode vir a melhorar a durabilidade desses compósitos, uma vez que reduziu sensivelmente sua capacidade de absorção.

PALAVRAS-CHAVE: compósito fibra vegetal-cimento, polímeros, MEV.

\section{DURABILITY OF CELLULOSE-CEMENT COMPOSITES MODIFIED BY POLYMER}

ABSTRACT: The durability of the cellulose-cement composites is a decisive factor to introduce such material in the market. Polymers have been used in concrete and mortar production to increase its durability. The goal of this work was the physical and mechanical characterization of cellulose-cement composites modified by a polymer and the subsequent durability evaluation. The work also evaluated the dispersion of acrylic polymer in composites made of Pinus caribaea residues. The physical properties observed were water absorption by immersion and bulk density. Rupture modulus and toughness were determined by flexural test. The specimens were obtained from pads, produced by pressing and wet curing. Samples were subjected to accelerated aging tests by repeated wetting and drying cycles and hot-water bath and natural aging. The scanning electron microscopy (SEM) allowed verifying the fiber and composite characteristics along the time. For the composite range analyzed, it was observed the polymer improved the mechanical properties of composites besides a significant decreasing in water absorption. The use of polymer improved the performance of vegetable fiber-cement composites when compared to the conventional mortar, due to water absorption decreasing.

KEYWORDS: polymer, fiber-cement composite, SEM.

\footnotetext{
1 Extraído da Tese de Doutorado do primeiro autor.

2 Prof. Dr., Faculdade de Arquitetura e Urbanismo, PUC, Campinas - SP.

3 Prof. Dr., Faculdade de Engenharia Agrícola, UNICAMP, Campinas - SP.

${ }^{4}$ Prof. Dr., Faculdade de Zootecnia e Engenharia de Alimentos, USP, Pirassununga - SP.

Recebido pelo Conselho Editorial em: 30-6-2005

Aprovado pelo Conselho Editorial em: 29-5-2006
} 


\section{INTRODUÇÃO}

Compósitos biomassa vegetal-cimento (CBVC) podem ser utilizados para as mais diversas finalidades em vista de suas características especiais, tais como, baixa massa específica, baixa condutividade térmica, resistência ao fogo, impermeabilidade e resistência mecânica que, embora não seja tão alta quanto a do concreto, mostra-se adequada para aplicações em placas delgadas de uso freqüente na construção civil. Produtos à base de aglomerantes inorgânicos e madeira começaram a ser produzidos a partir da década de 1930 sob a forma de painéis leves de madeira e magnesita. O desenvolvimento da tecnologia para utilização de resíduos de madeira com aglomerantes orgânicos efetuou-se mais rapidamente do que a utilização dessa matéria-prima vegetal com aglomerantes minerais (BERALDO, 1997).

Atualmente, devido ao encarecimento dos aglomerantes orgânicos e à proibição da utilização do amianto em alguns países, pesquisas sobre a viabilidade da utilização de compósitos biomassa vegetal-cimento voltaram a ser desenvolvidas. Outro fator que impulsiona a ampliação dessa linha de pesquisa é a preocupação com o meio ambiente. Busca-se, por meio da utilização de resíduos provenientes da agroindústria, minimizar o gasto de energia para a produção de elementos construtivos e evitar danos ao ambiente, causados pela queima desses resíduos.

Em todo o mundo, esses fibrocimentos alternativos já fazem parte de programas de transferência tecnológica, especialmente no que se refere aos sistemas de cobertura de baixo custo (GRAM et al., 1994 citados por SAVASTANO JÚNIOR, 2000).

Existem três classes principais de concretos utilizando polímeros: o concreto de cimento Portland impregnado por polímero, que, após o endurecimento, recebe impregnação de resina polimérica; o concreto modificado por polímero, em que o polímero é empregado na forma de dispersão em água (látex) juntamente com a água de amassamento no processo de mistura do concreto, e o concreto polímero, em que o aglomerante é uma resina polimérica, podendo o cimento Portland ser empregado como filler ou não. A utilização dessas técnicas visa a melhorar as propriedades, como a ligação entre o concreto e o substrato, a resistência ao impacto, à penetração de água e sais dissolvidos e a ação de congelamento e degelo (ACI, 1997).

As características do concreto reforçado com fibras dependem muito da resistência mecânica da matriz, do seu módulo de deformação e da sua adesão com as fibras. Modificações nessas características podem otimizar a eficiência das fibras e aumentar sua durabilidade na matriz cimentícia.

A incompatibilidade física é resultado das diferenças significativas na movimentação higroscópica das fibras e da argamassa. As fibras tendem a se movimentar mais, e tal fato gera esforços mecânicos cíclicos na matriz, os quais podem levar à microfissuração generalizada. A utilização de polímero para aumentar a aderência entre a fibra e a matriz, além de reduzir a absorção de água pela fibra, pode ajudar a reduzir tais esforços mecânicos.

Neste trabalho, foram observadas as características físicas e mecânicas e a degradação de compósitos fibra vegetal-cimento modificados por polímeros de base acrílica, comparando-as com o compósito sem adição de polímeros.

\section{MATERIAL E MÉTODOS}

O resíduo de Pinus caribaea, fornecido pela indústria Faber Castell, foi proveniente da unidade de Prata - MG, onde está localizada a unidade florestal e a serraria, na qual é realizado o primeiro desdobro da madeira para a produção de lápis. O resíduo foi utilizado no experimento tal como fornecido pela indústria, sendo a distribuição em tamanho das partículas apresentada na Figura 1. 


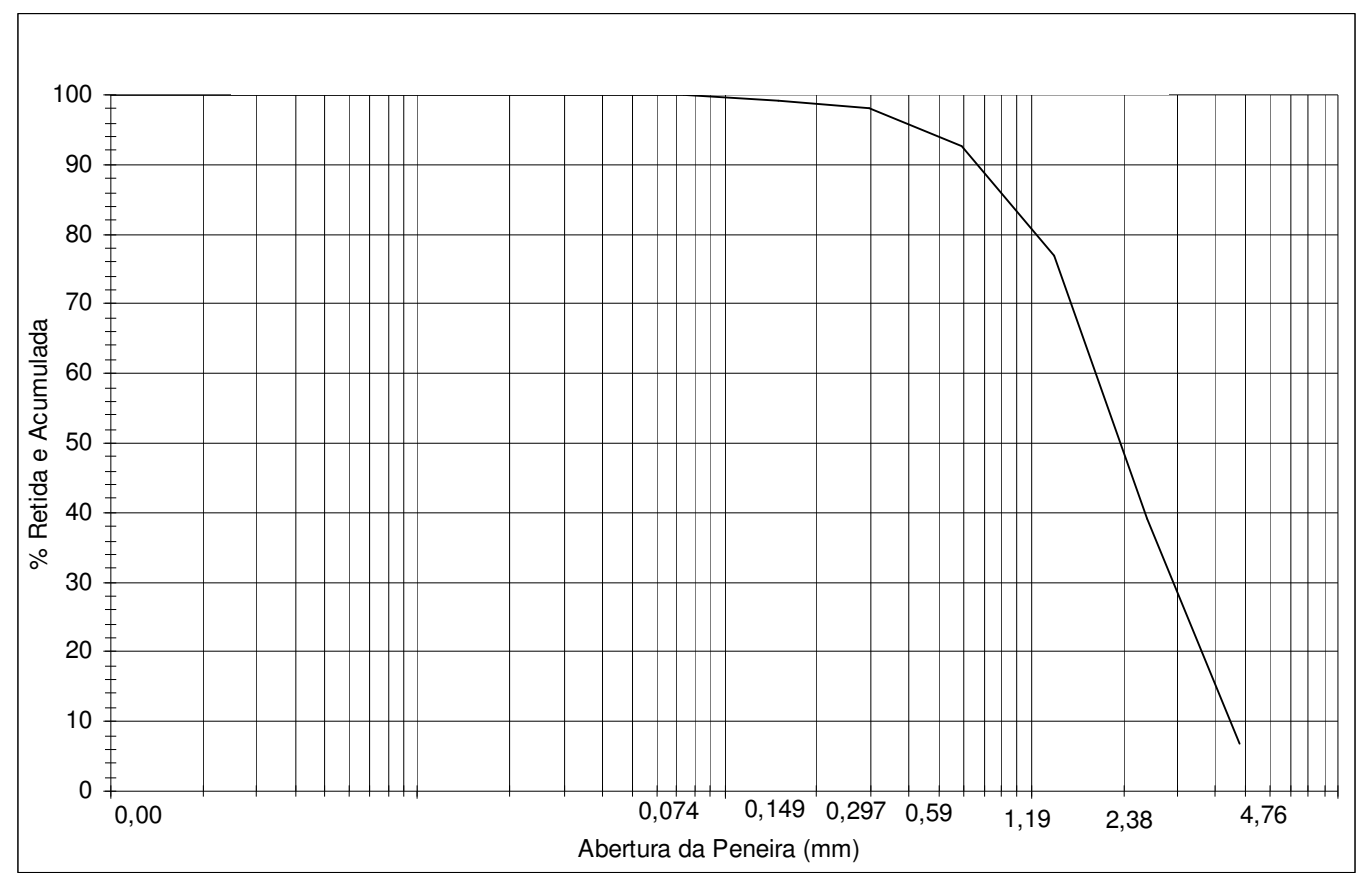

FIGURA 1. Distribuição em tamanho - resíduo de Pinus caribaea.

A granulometria da areia utilizada apresentou módulo de finura igual a 2,72 e diâmetro máximo igual a 4,8 mm, sendo, portanto, classificada como areia média, segundo a NBR 7211 (ABNT, 1983).

O cimento utilizado foi o CP V-ARI fornecido pela CIMINAS. Foi utilizado polímero de base acrílica fornecido pela MTB, o RHEOMIX 125. Esse produto foi caracterizado pela determinação do teor de sólidos e do seu $\mathrm{pH}$, cujos valores são, respectivamente, $\mathrm{TS}=34,2 \%$ e $\mathrm{pH}=8,19$. A determinação do teor de sólidos foi feita em balança com dispositivo de secagem por infravermelho, até constância de massa, à temperatura máxima de $100^{\circ} \mathrm{C}$.

Foram utilizadas proporções de $1 ; 5$ e $10 \%$ de polímero seco em relação à massa de cimento. A nomenclatura utilizada para o resíduo de pínus foi (S). Para os tratamentos, testemunha (0), com adição de polímero, teor de $1 \%$ (1), teor de 5\% (5) e teor de 10\% (10).

A formulação do compósito foi baseada em estudo realizado por PIMENTEL (2000): 1:1,25:0,15 (cimento:areia:resíduo de pínus, em massa) e relação água-cimento a/c = 0,55.

Os componentes foram misturados a seco e, em seguida, adicionada a água de amassamento com o polímero previamente diluído. O material foi distribuído na fôrma $(210 \mathrm{~mm}$ x $600 \mathrm{~mm} \times$ $10 \mathrm{~mm}$ ) e prensado sob pressão de 1,6 MPa por 24 h e após, imerso em água até a idade de 28 dias. De cada placa, foram extraídos 13 corpos-de-prova de dimensões $40 \mathrm{~mm}$ x $200 \mathrm{~mm}$ x $10 \mathrm{~mm}$. Na Figura 2, apresenta-se a sequiência de preparação das placas. Foram produzidas dez repetições para cada dosagem e idade de envelhecimento.
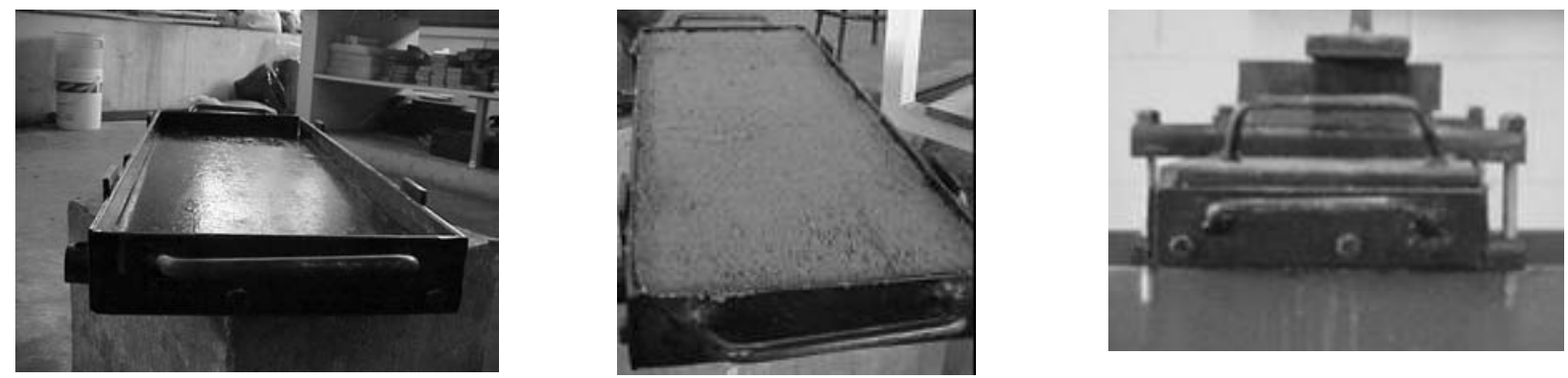

FIGURA 2. Seqüência de produção das placas com compósito à base de pínus. 


\section{Método de ensaio}

Os corpos-de-prova foram submetidos ao ensaio de flexão com quatro apoios. Foi utilizada máquina universal de ensaios, marca EMIC, modelo DL 30000, célula de carga de $1 \mathrm{kN}$ e programa de controle M-Test v.1.01/96. A velocidade de carregamento adotada foi de $5 \mathrm{~mm} \mathrm{~min}{ }^{-1}$ e, ao se constatar redução de $60 \%$ da carga máxima de ruptura, interrompia-se o ensaio de forma a padronizar o cálculo da energia absorvida. Este ensaio seguiu procedimento utilizado por SAVASTANO et al. (2000). Os dados de absorção de água e a densidade foram obtidos dos corpos-de-prova do teste de flexão, seguindo os procedimentos especificados na ASTM C 948-81 (ASTM, 1982). Os resultados foram submetidos à análise de variância e ao teste de Tukey para as médias, a 0,05 de significância.

Foram adotados dois ensaios de envelhecimento acelerado: imersão em água quente $(60 \pm$ $2{ }^{\circ} \mathrm{C}$ ), durante 56 dias, e ciclos de molhamento e secagem, constituindo-se de $18 \mathrm{~h}$ de imersão em água à temperatura ambiente, e de $6 \mathrm{~h}$ em estufa $\left(60 \pm 5^{\circ} \mathrm{C}\right)$, ambos conforme norma UNE EN 494:1994. De cada tratamento, foram separados, aleatoriamente, dez corpos-de-prova para serem submetidos a cada um desses processos de envelhecimento. Após a realização dos ciclos de envelhecimento acelerado, os corpos-de-prova foram ensaiados à flexão e tiveram seus índices físicos determinados.

O envelhecimento natural foi realizado de duas formas: mantendo-se os corpos-de-prova em ambiente interno ao laboratório e expondo-os ao tempo, em bancada com inclinação de $30 \%$ em relação à horizontal e voltados em direção ao norte verdadeiro, de forma a maximizar a incidência de raios solares. O teste foi realizado no Campo Experimental da Faculdade de Engenharia Agrícola - Unicamp, em Campinas - SP, cuja localização geográfica é latitude (S) 22\%55', longitude (W) $47^{\circ} 05^{\prime}$ e aproximadamente $640 \mathrm{~m}$ de altitude. A temperatura média anual é de $21,6^{\circ} \mathrm{C}$, o índice pluviométrico médio igual a $1.382 \mathrm{~mm}$, a umidade relativa de $72 \%$ e o clima classificado como tropical de altitude. De cada dosagem e material, foram colocados dez corpos-de-prova para seis meses e a mesma quantidade para um ano de envelhecimento; a mesma quantidade de corposde-prova foi colocada para envelhecimento protegido (laboratório). Os corpos-de-prova foram colocados em exposição em julho de 2003.

Fragmentos de corpos-de-prova, após os ensaios de durabilidade acelerada e natural, foram separados e mantidos imersos em álcool isopropílico, para interromper o processo de hidratação do cimento, sendo posteriormente analisados por microscopia eletrônica. Parte dos ensaios foi desenvolvida no Laboratório de Microscopia do Instituto Militar de Engenharia, em equipamento marca JEOL, modelo JSM 5800, graças ao projeto de pesquisa interinstitucional CAPES-PROCAD n⿳ 0215/01-6 "Materiais de construção à base de cimentos alternativos reforçados com fibras vegetais e polpas celulósicas - caracterização e análise de durabilidade". Outra parte dos ensaios foi realizada no Laboratório Nacional de Luz Síncroton, utilizando equipamento JSM-5900LV.

Foram feitas imagens usando elétrons retroespalhados (BSEI), na análise de amostras de seção plana, que foram preparadas embutidas em baquelite. Em seguida, as amostras foram polidas com pasta de alumina e posteriormente metalizadas com ouro. Esse tipo de amostra permite o contraste entre as diversas fases do compósito, pela diferença de número atômico dos constituintes: quanto menos denso for o material, mais escura será a imagem. Imagens com elétrons secundários foram realizadas na análise de amostra fraturada (SEI); nesse caso, a imagem permite observar a morfologia da superfície do corpo-de-prova.

\section{RESULTADOS E DISCUSSÃO}

O procedimento de comparação múltipla aplicado à variável (absorção de água e massa específica), em função do fator traço, indica os grupos homogêneos estatisticamente diferentes entre si, com 95\% de confiança, e são apresentados em ordem crescente de incremento, na Tabela 1. Observa-se que a adição de polímero reduziu a capacidade de absorção em todos os compósitos. A massa específica do compósito não foi sensível à adição de polímero. 
TABELA 1. Comparação múltipla de características físicas em função do traço.

\begin{tabular}{cc}
\hline Propriedade & Compósito com pínus \\
\hline Absorção de água & $\mathrm{S} 10<\mathrm{S} 5<\mathrm{S} 0=\mathrm{S} 1$ \\
Massa específica aparente & $\mathrm{S} 0=\mathrm{S} 1=\mathrm{S} 5=\mathrm{S} 10$ \\
\hline
\end{tabular}

Nas Figuras 3 e 4, apresentam-se os gráficos de valores médios de absorção de água em função do processo de envelhecimento do compósito. Constata-se que a tendência de redução da capacidade de absorção de água com a adição do polímero, observada na análise estatística, se mantém para os compósitos após cada processo de envelhecimento.

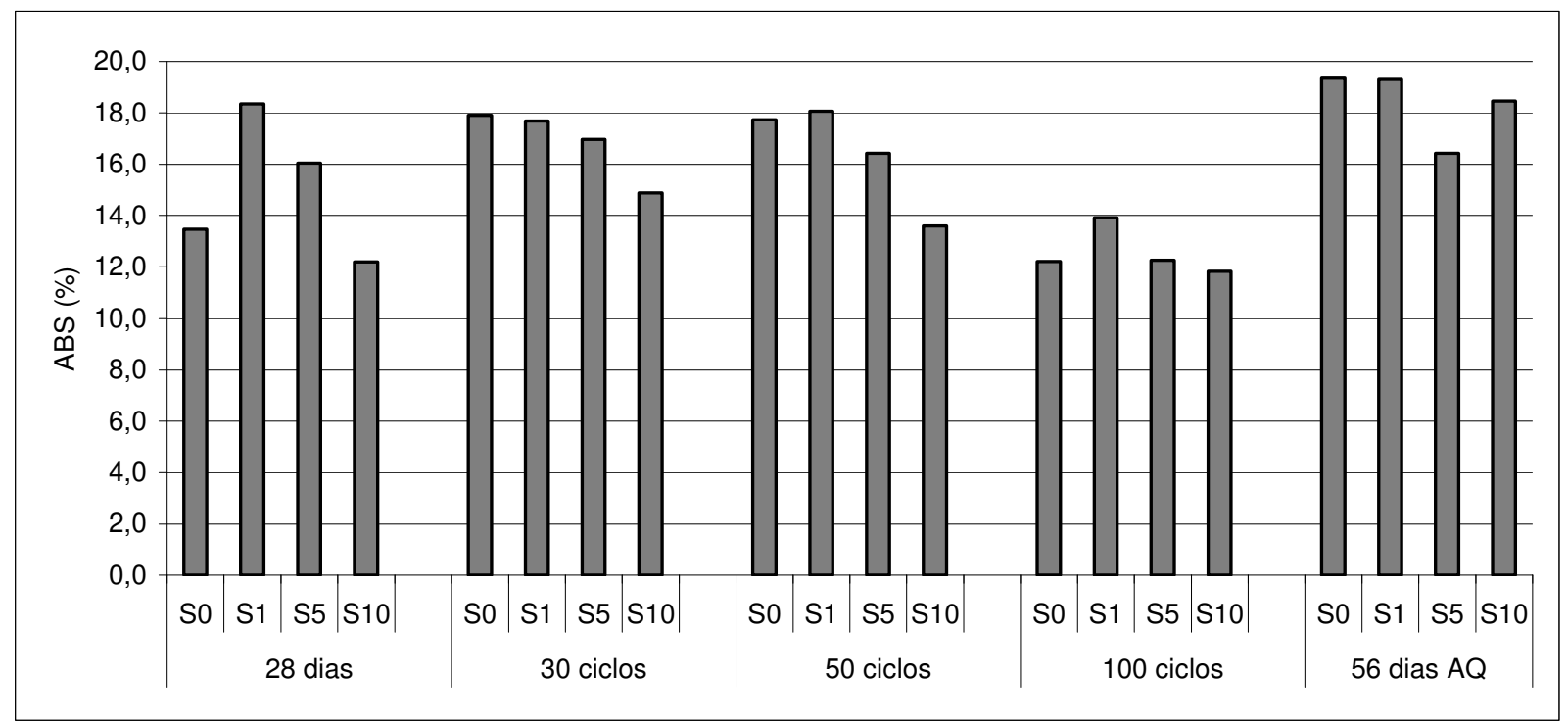

FIGURA 3. Valores médios de absorção em função do envelhecimento acelerado.

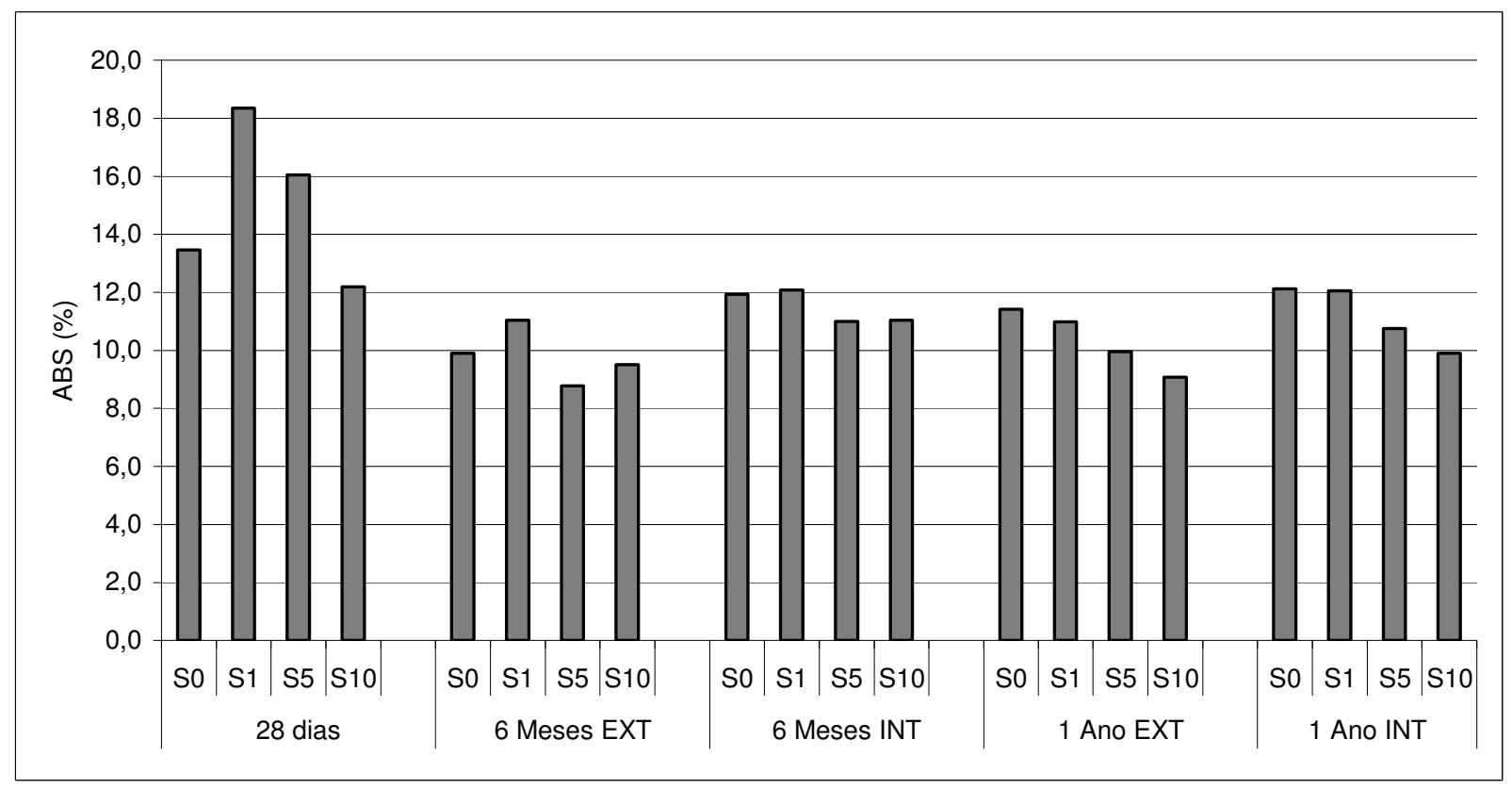

FIGURA 4. Valores médios de absorção em função do envelhecimento natural.

Após os corpos-de-prova serem submetidos ao processo de envelhecimento acelerado, a capacidade de absorção de água aumentou, principalmente para o processo de envelhecimento por imersão em água quente. A permeabilidade do compósito é prejudicada logo nas primeiras idades do processo de envelhecimento acelerado. No entanto, após seis meses e um ano de envelhecimento natural, a capacidade de absorção é significativamente reduzida. Essa redução da 
capacidade de absorção pode ser explicada pela continuidade do processo de hidratação e pela colmatação propiciada pela migração do $\mathrm{CaCO}_{3}$ produzido pela carbonatação, fechando os poros e tornando o compósito menos permeável. O processo de carbonatação foi verificado por meio do ensaio de aspersão de solução de fenolftaleína sobre a região de fratura do corpo-de-prova e como pode ser observado na Figura 5.

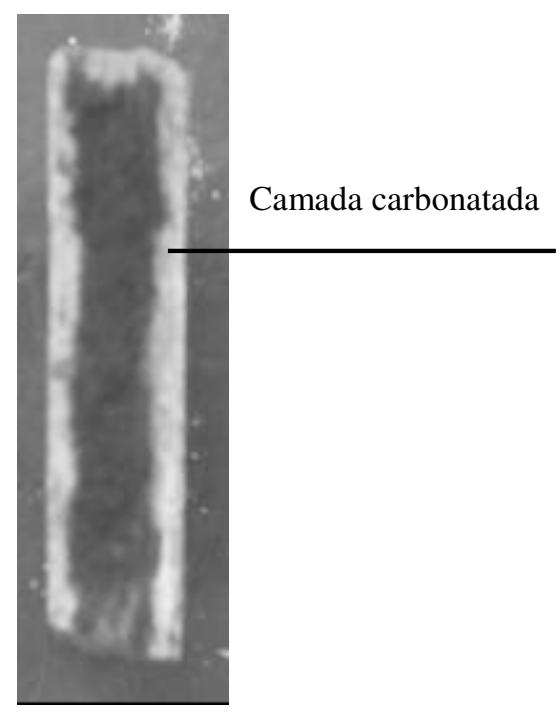

FIGURA 5. Ensaio com fenolftaleína para a determinação da profundidade de carbonatação.

Na Tabela 2, apresenta-se o resultado das tabelas de comparação múltipla para as características mecânicas (tensão de ruptura de tração na flexão e energia específica) em função do traço. A adição de polímero aumenta a resistência à tração na flexão e a energia específica para todos os compósitos.

TABELA 2. Comparação múltipla de características mecânicas em função do traço.

\begin{tabular}{cc}
\hline Propriedade & Compósito com pínus \\
\hline Módulo de ruptura & $\mathrm{S} 0=\mathrm{S} 1<\mathrm{S} 10=\mathrm{S} 5$ \\
Energia específica & $\mathrm{S} 0=\mathrm{S} 1<\mathrm{S} 5<\mathrm{S} 10$ \\
\hline
\end{tabular}

O compósito com adição de $10 \%$ de polímero apresentou melhor desempenho mecânico na idade de 28 dias. O compósito com 10\% de adição de polímero atingiu, aos 28 dias, 5,4 MPa de resistência à tração na flexão, enquanto o compósito sem adição de polímero atingiu 4,4 MPa.

Os processos de envelhecimento acelerado, mesmo nas idades iniciais, afetaram o desempenho mecânico do compósito, reduzindo bruscamente sua resistência à tração na flexão e sua tenacidade. Nas Figuras 6 e 7, apresentam-se os valores médios obtidos de resistência à tração na flexão. Além da redução brusca da resistência após o envelhecimento acelerado, nota-se o significativo aumento da resistência após o envelhecimento natural. A adição do polímero tornou o compósito menos sensível ao envelhecimento acelerado, isto é, a redução da resistência não é drástica como para o compósito sem adição de polímero.

Os valores de resistência para os traços com $5 \%$ e $10 \%$ de adição de polímero são estatisticamente iguais, por isso a adição de $5 \%$ de polímero seria o teor mais indicado para esse compósito. 


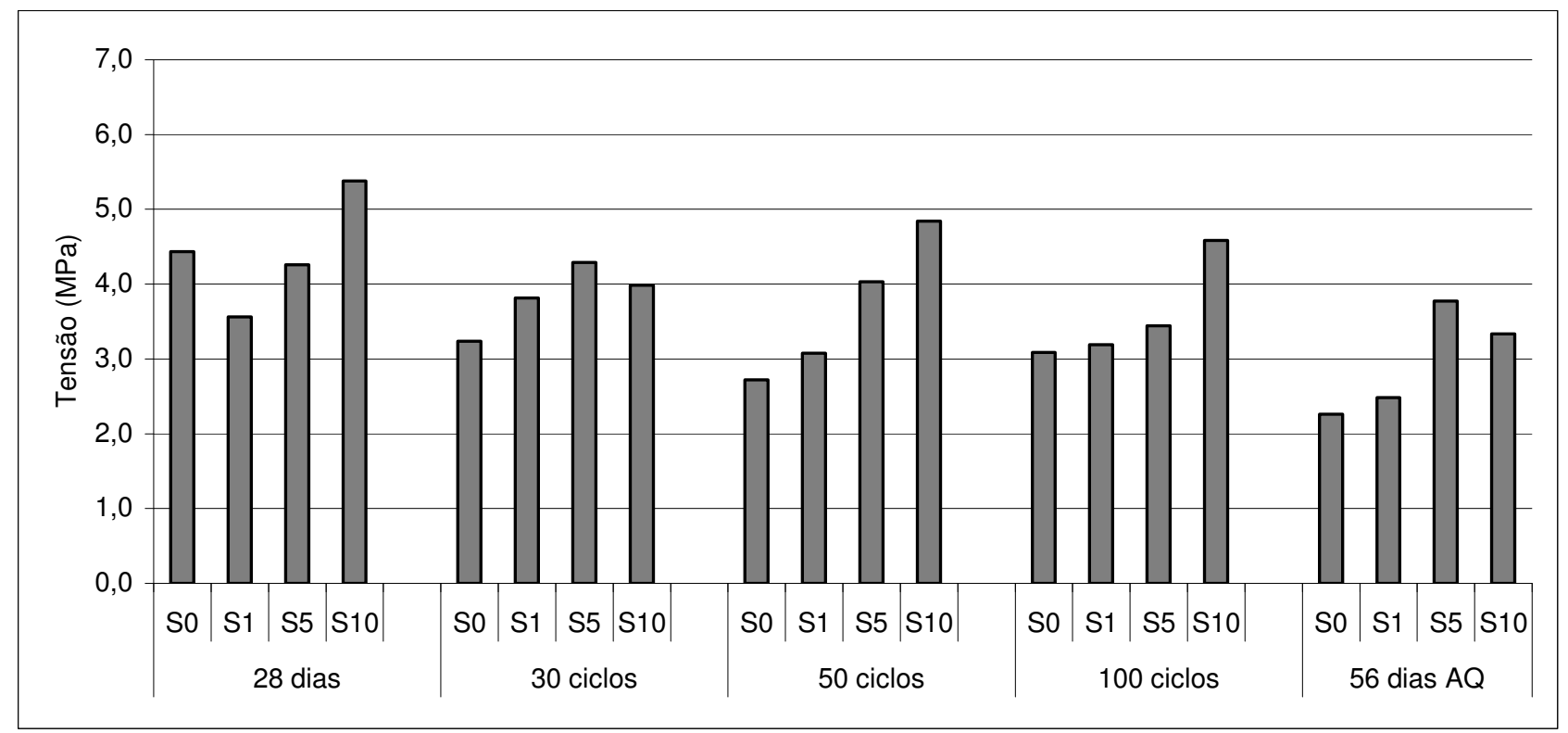

FIGURA 6. Média de resistência em função da adição de polímero e do processo de envelhecimento acelerado.

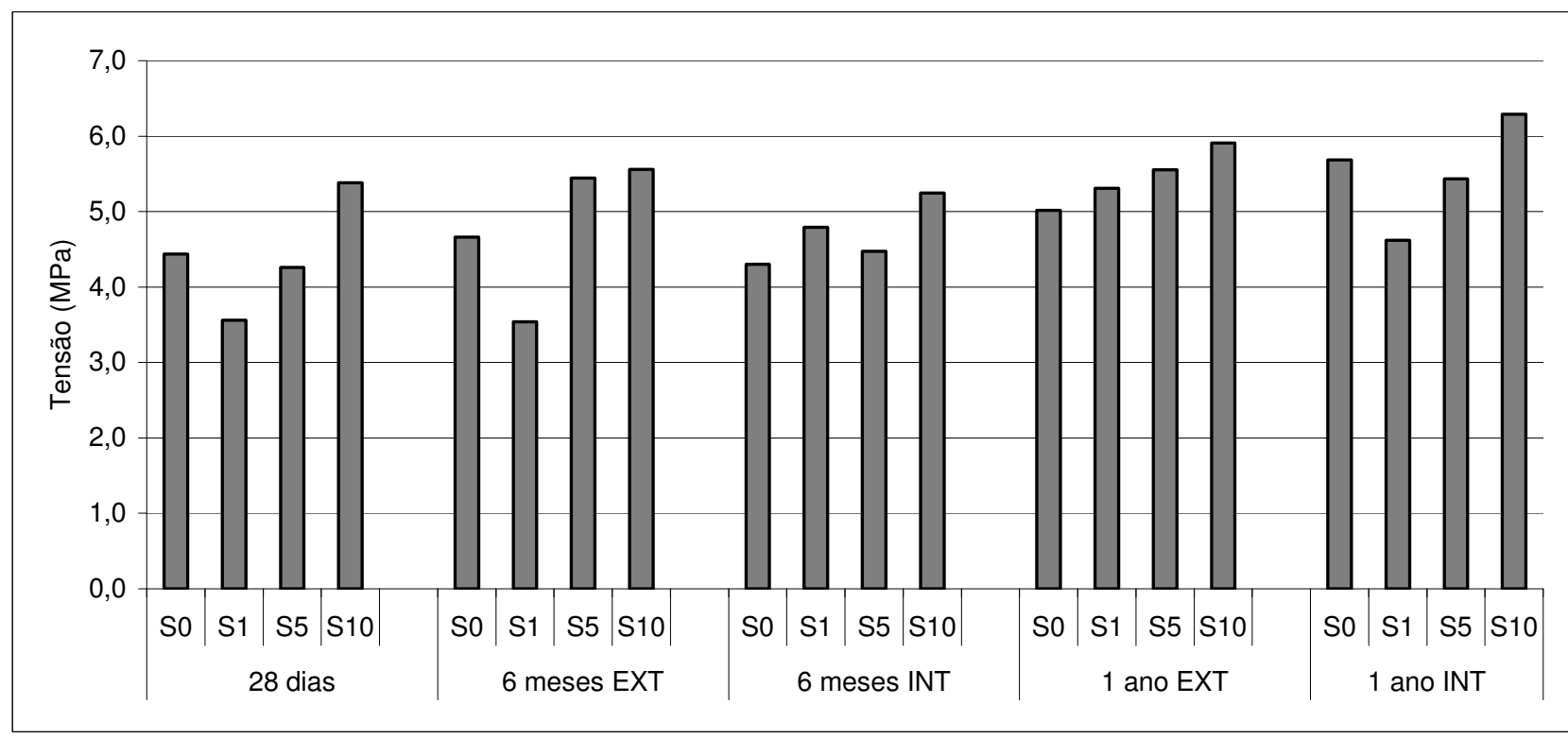

FIGURA 7. Média de resistência em função da adição de polímero e do processo de envelhecimento natural.

Nas Figuras 8 a 10, apresenta-se a evolução da resistência do compósito após os ensaios de envelhecimento. O compósito sem adição de polímero (S0), após ser submetido aos processos de envelhecimento acelerado, não ganhou resistência e tornou-se mais frágil, pois a tenacidade reduziu-se $\left(0,74 \mathrm{~kJ} \mathrm{~m}^{-2}\right.$ aos 28 dias; $0,41 \mathrm{~kJ} \mathrm{~m}^{-2}$ após 30 ciclos; $0,46 \mathrm{~kJ} \mathrm{~m}^{-2}$ após 50 ciclos; $0,4 \mathrm{~kJ} \mathrm{~m}^{-2}$ após 100 ciclos e $0,41 \mathrm{~kJ} \mathrm{~m}^{-2}$ após envelhecimento em água quente). Essa tendência manteve-se para os compósitos com adição de polímero. Para todos os compósitos, observou-se ganho de resistência e tenacidade após seis meses e um ano de envelhecimento natural, principalmente para o compósito com $10 \%$ de adição de polímero, o que pode ser explicado, em parte, pela continuidade do processo de hidratação.

O processo de imersão em água quente mostrou-se mais agressivo do que o processo de ciclos de imersão e secagem, principalmente para compósitos com adição de polímero. Em discussão durante o Seminário "Compósitos Cimento-Polímeros", realizado em 4 de novembro de 2004 na FZEA-USP, em Pirassununga, pesquisadores relataram a fragilidade de compósitos 
modificados por polímeros após ensaios de envelhecimento acelerado com presença de umidade e alta temperatura, considerando a necessidade de propor novos métodos para ensaio desse material.
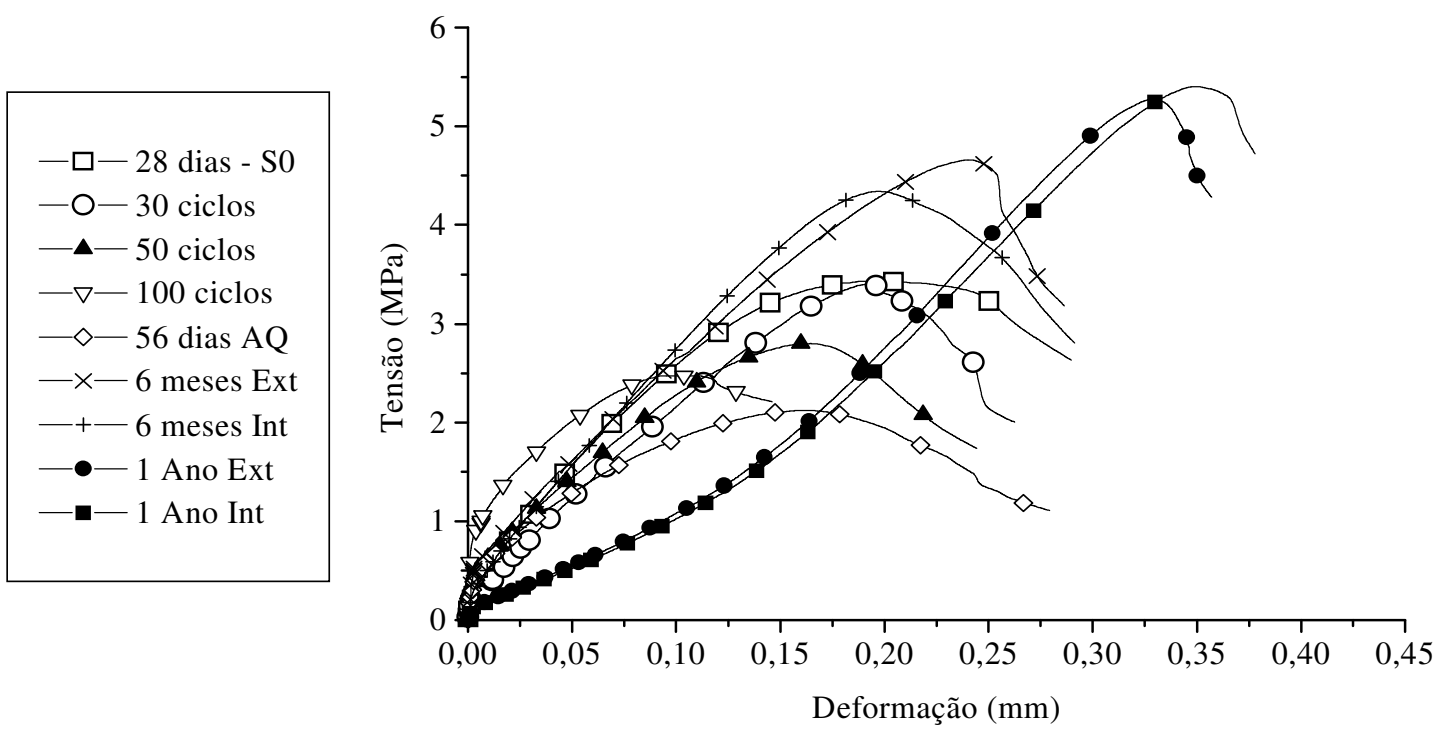

FIGURA 8. Evolução da resistência do compósito S0 após ensaios de envelhecimento.
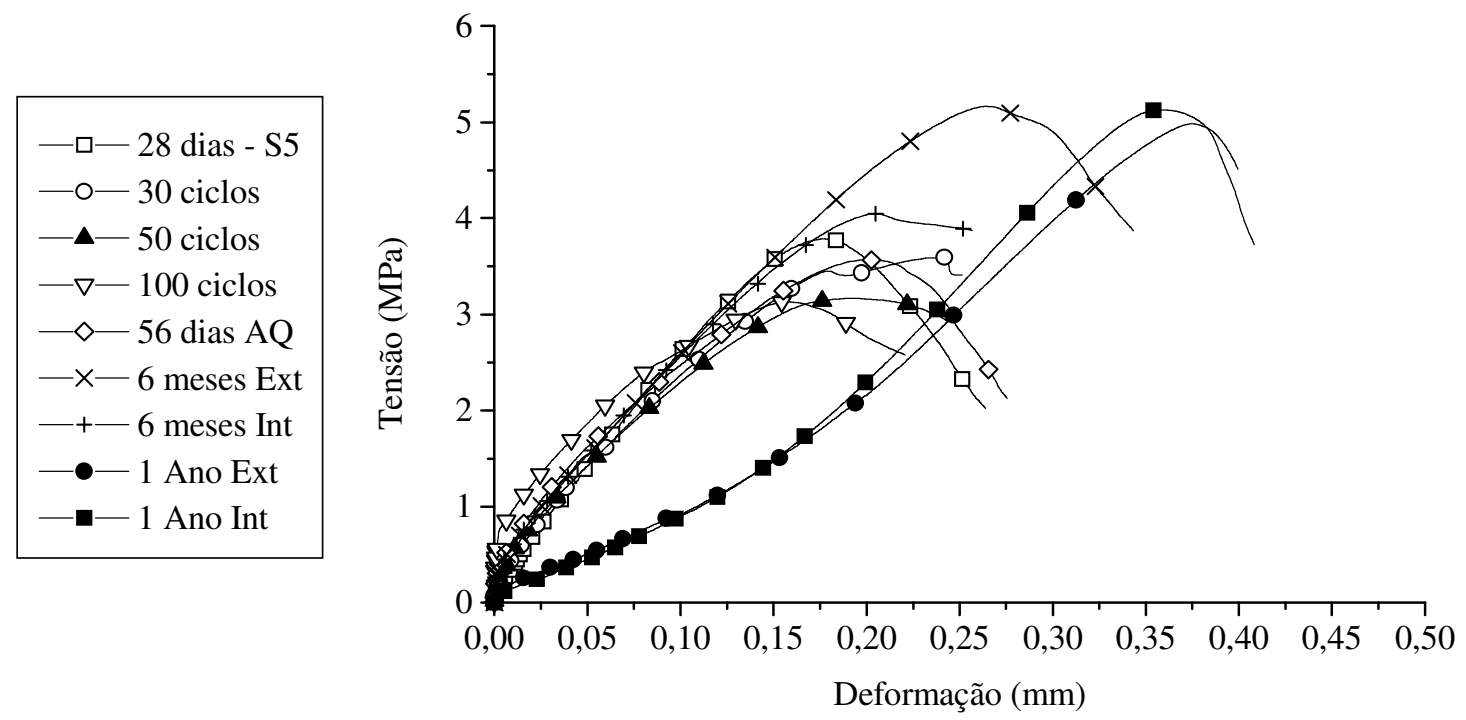

FIGURA 9. Evolução da resistência do compósito S5 após ensaios de envelhecimento. 


$$
\begin{array}{|l|}
\hline \square-28 \text { dias }-\mathrm{S} 10 \\
-\mathrm{O}-30 \text { ciclos } \\
-\Delta-50 \text { ciclos } \\
-\nabla-100 \text { ciclos } \\
-\diamond-56 \text { dias AQ } \\
-\times-6 \text { meses Ext } \\
-+-6 \text { meses Int } \\
-\square-1 \text { Ano Ext } \\
-\square-1 \text { Ano Int } \\
\hline
\end{array}
$$

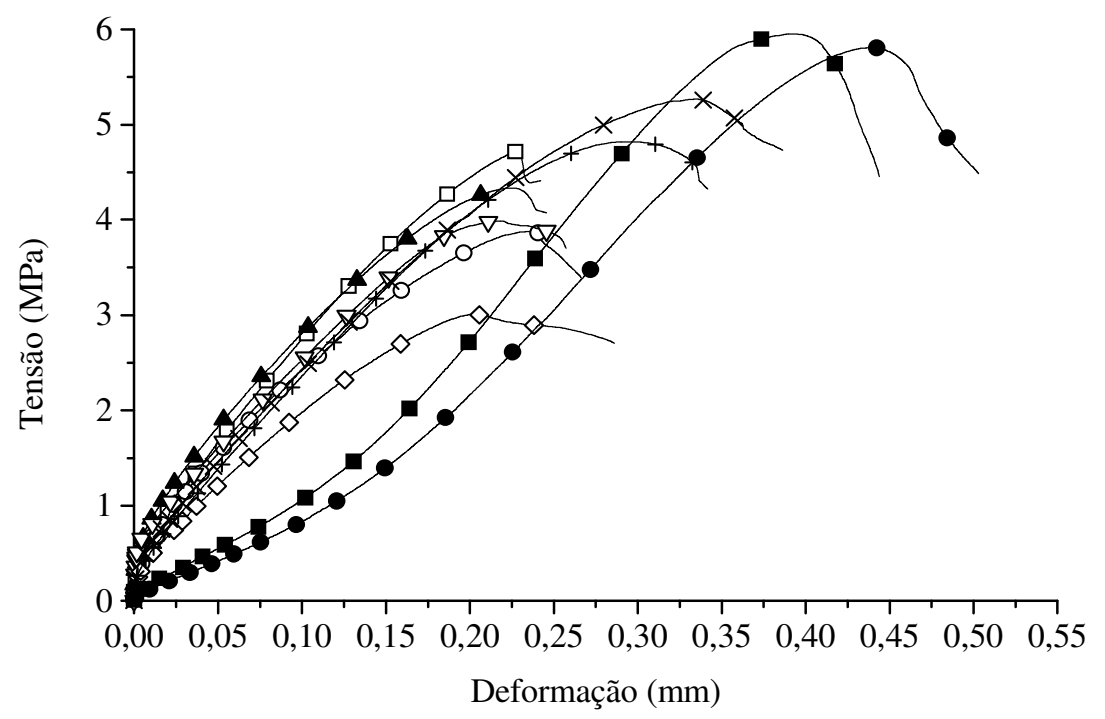

FIGURA 10. Evolução da resistência do compósito S10 após ensaios de envelhecimento.

Na Figura 11, apresenta-se micrografia do compósito com 10\% de adição de polímero, aos 28 dias de idade. Nesse detalhe, observa-se o preenchimento de elementos anatômicos da madeira por produtos da hidratação do cimento, não tendo sido observados descolamentos entre a matriz e as partículas de pínus, aparentando existir boa aderência entre eles.

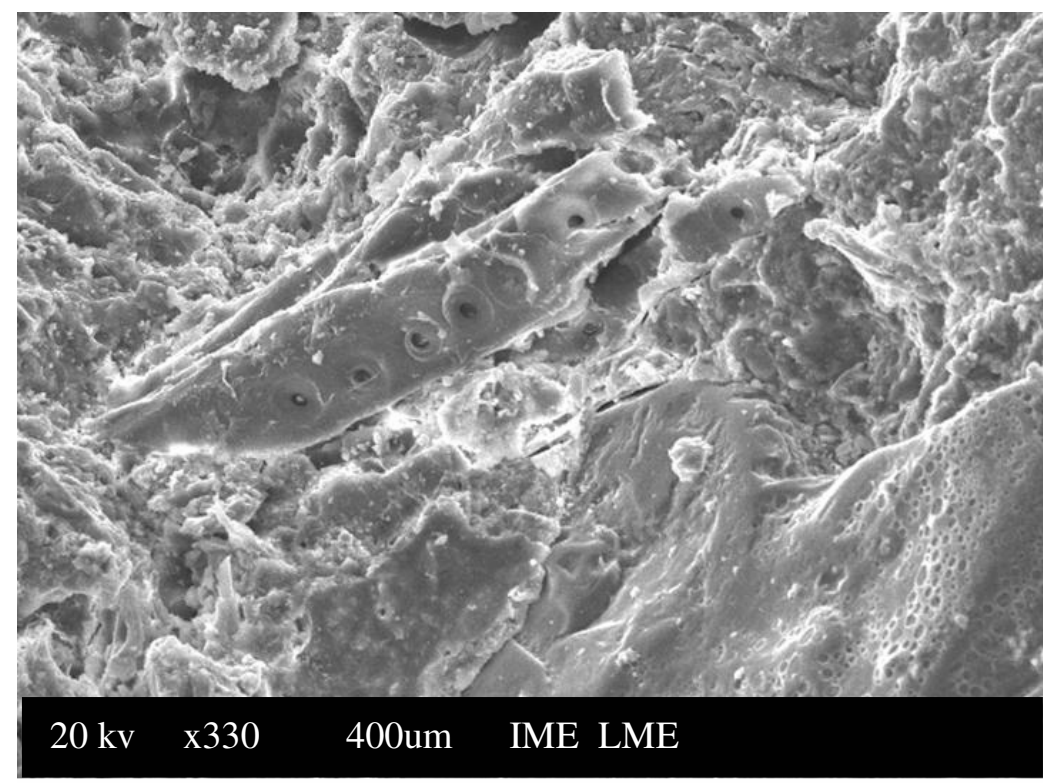

FIGURA 11. Micrografia do compósito S10 - 28 dias. IME

\section{CONCLUSÕES}

A adição de polímero promoveu significativa redução da capacidade de absorção de água e aumento da resistência à tração na flexão, denotando sua adequação para aumentar a durabilidade do compósito.

O processo de envelhecimento acelerado por imersão em água quente reduziu significativamente a resistência e a tenacidade dos compósitos, além de aumentar a capacidade de absorção de água, mostrando-se um processo de avaliação extremamente agressivo. 
Após o processo de envelhecimento natural, a capacidade de absorção de água dos compósitos sofreu redução, sendo mais evidente para compósitos com adição de polímero; tal fato pode ser justificado pelo processo de carbonatação que provoca colmatação dos poros superficiais.

Ocorreu também significativo aumento da resistência à tração na flexão para idade de seis meses e um ano de envelhecimento natural externo e interno, comparada à resistência inicial aos 28 dias.

A adição do polímero tornou o compósito menos sensível ao envelhecimento acelerado. A adição do teor de 5\% seria a mais adequada, visto que não houve diferença estatística significativa entre as resistências para todas as idades e/ou condições de envelhecimento obtidas entre os compósitos com 5 e $10 \%$ de polímero.

\section{AGRADECIMENTOS}

Ao CNPq, pelo apoio financeiro e pelas bolsas de Produtividade em Pesquisa para o segundo e o terceiro autores; às empresas CIMINAS e MTB, pelo fornecimento de materiais; ao Laboratório de Microscopia Eletrônica do Instituto Militar de Engenharia do Rio de Janeiro, pela execução de parte dos ensaios de microscopia, e ao Laboratório Nacional de Luz Sincroton de Campinas.

\section{REFERÊNCIAS}

AMERICAN CONCRETE INSTITUTE. ACI 548.3R-95: Manual of concrete practice. part 4, p.148, 1997.

AMERICAN SOCIETY FOR TESTING AND MATERIALS. ASTM C 948-81: Dry and wet bulk density, water absorption and apparent porosity of thin sections of glass-fiber-reinforced concrete, test for - Annual Book of ASTM Standards Philadelphia, 1982. v.16.

ASSOCIAÇÃO BRASILEIRA DE NORMAS TÉCNICAS. NBR 7211: Agregados para concreto, especificação. Rio de Janeiro, 1983. 5 p.

BERALDO, A.L. Materiais não-convencionais para construções rurais. In: SIMPÓSIO MATERIAIS NÃO-CONVENCIONAIS PARA CONSTRUÇÕES RURAIS, 1997, Campina Grande. Anais... Campina Grande: Editora Marcone, 1997. cap.1, p.1- 48.

PIMENTEL, L.L. Viabilidade da fabricação de telhas onduladas utilizando compósito à base de Pinus caribaea. 2000. 67 f. Dissertação (Mestrado em Construções Rurais e Ambiência) Faculdade de Engenharia Agrícola, UNICAMP, Campinas, 2000.

SAVASTANO JÚNIOR, H. Materiais à base de cimento reforçados com fibra vegetal: reciclagem de resíduos para a construção de baixo custo. 144 f. Tese (Livre-Docência em Materiais e Componentes de Construção) - Escola Politécnica da Universidade de São Paulo, São Paulo, 2000.

SAVASTANO JÚNIOR, H.; WARDEN, P.G.; COUTTS, R.S.P. Low-cost matrices for cellulosecement materials. In: SYMPOSIUM ON CONSTRUCTION \& ENVIRONMENT: Theory into Practice, 2000, São Paulo. Anais... São Paulo: Global Seven, 2000. p.1-10. 